\title{
MSWI bottom ash for thermal energy storage: An innovative and sustainable approach for its reutilization
}

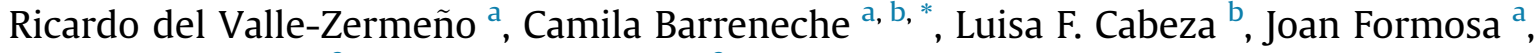 \\ A. Inés Fernández ${ }^{a}$, Josep M. Chimenos ${ }^{a}$ \\ a Materials Science and Engineering, Universitat de Barcelona, Martí i Franqués 1-11, Barcelona, 08028, Spain \\ ${ }^{\mathrm{b}}$ GREA Innovació Concurrent, Universitat de Lleida, Edifici CREA, Pere de Cabrera s/n, 25001, Lleida, Spain
}

\section{A R T I C L E I N F O}

\section{Article history:}

Received 17 February 2016

Received in revised form

11 July 2016

Accepted 12 July 2016

Available online 27 July 2016

\section{Keywords:}

Bottom ash

Thermal energy storage (TES)

Sensible heat storage (SHS)

By-product

\begin{abstract}
A B S T R A C T
The management of Municipal Solid Waste (MSW) is a very important issue that must be dealt by the perspective of the 3 Rs (Reuse, reduce, recycle. MSW incineration bottom ash (BA) accounts for $85-95 \%$ of the total solids that remained after incineration. Finding suitable alternatives for its revalorization is very attractive, especially in terms of environmental sustainability. Thermal energy storage (TES) is a complementary technology of renewable energy. The aim of this study is to evaluate the thermophysical properties of weathered BA (WBA) in order to find suitable alternatives for its valorisation. Several samples of WBA were collected from a waste-to-energy facility located in Tarragona (Spain). This facility sieved to different size fractions. Each size fraction was characterized with respect its physicochemical properties and the energy density $\left(\rho_{e n}\right)$ was calculated. The results obtained showed that this residue is a suitable alternative candidate material for TES as it presents an energy density of $1461.2 \mathrm{~kJ} \mathrm{~m}^{-3} \mathrm{~K}^{-1}$ for the $1-2 \mathrm{~mm}$ fraction. In addition, the low cost of this type of residue $(0.6 €$ per $\mathrm{t})$ and its high production rate per year makes it an attractive and sustainable alternative for TES.
\end{abstract}

(C) 2016 Elsevier Ltd. All rights reserved.

\section{Introduction}

The management of Municipal Solid Waste (MSW) is a very important issue that must be dealt by the perspective of the $3 \mathrm{Rs}$ (Reduce, Reuse and Recycle) [1]. In this sense, incineration has become a valuable alternative as it allows reducing waste mass by $70 \%$ and volume by up to $90 \%$, apart from producing energy from the heat of combustion [2,3]. However, at the end of the process, an average $30 \%$ of the total content remains in the form of two main residues: bottom ash (BA) and air pollution control (APC) residues. BA accounts for $85-95 \%$ of the total solids and it can be described as a heterogeneous mixture of grate ash and grate siftings that contain slag, ferrous and non-ferrous metals, ceramics, glass, other noncombustibles and residual organic matter [4-6]. It is classified as a non-hazardous waste by the European Waste Catalogue because it is typically rich in calcium, aluminum, silicon, and iron [7]. For this reason, it is commonly reused as secondary building material,

\footnotetext{
* Corresponding author. Materials Science and Engineering, Universitat de Barcelona, Martí i Franqués 1-11, Barcelona, 08028, Spain.

E-mail address: cbarreneche@diei.udl.cat (C. Barreneche).
}

mainly as raw material for clinker, cement mortar or frit production, as drainage layer in landfills, or as sub-base material in road construction [1,8-11]. Tatsidjodoung et al. presented several materials to be used as sensible heat storage materials with potential to be applied in building applications [12] and they concluded that water remains the most widely used material in sensible heat storage systems and the effects of various parameters such as the shape and size of the packing materials and the void fraction on the system performance in packed bed systems are nowadays under investigation. Some examples are: granite, marble, steel slab, aluminum, copper, etc.

However, prior to reutilization, BA must be subjected to a stabilization process aimed at reducing the potential risk of leaching toxic elements. Natural weathering is the most cost-effective stabilization treatment method, since it results in the chemical stability of weathered BA (WBA) [13]. Overall, the composition of WBA can be divided into two major groups [14]: (i) refractory waste products and (ii) melt products. The former group includes synthetic ceramics, rock and mineral fragments, various waste metals and unmelted glass shards, and the latter covers complex silicate minerals, isotropic and opaque glasses. Prior to weathering, BA is commonly subjected to a conditioning and revalorization process 
that is aimed at recovering ferrous and non-ferrous metals. However, these processes (commonly carried out by means of magnetic and Eddie current separators) are only effective in recovering the coarse fractions [15]. Therefore, especially for the fine fractions, the content of ferrous and non-ferrous metals could be a significant source of valuable resources.

Finding suitable alternatives for their revalorization is very attractive, especially in terms of environmental sustainability. Many of the consequences to the environment are regarded to come from the increased production of waste and emissions and the increased consumption of raw materials and energy. In this regard, energy consumption is increasing its ratio every year at a worldwide level as it was described by the International Platform of Climate Change (IPCC) [16]. 80\% of the total energy consumption in the OCDE countries is used in the building, industry and transport sectors [17]. In the framework of this issue, thermal energy storage (TES) is a technology able to avoid the thermal gap between the energy supply and its demand by reducing the peak load. There is a big expectation in deploying this technology in order to reduce the energy consumption while dealing with promisingly low $\mathrm{CO}_{2}$ and greenhouse gas emissions in the future. Moreover, TES is a complementary technology that allows overcoming the barriers that renewable energy technology presents. It can store energy by following three different methods: using sensible heat (SHTES) accumulated when a temperature gradient is applied; latent heat (LHTES) from the change of state of one material from solid-liquid, liquid-vapour, and solid-solid; and using the thermochemical (TCTES) heat produced or absorbed during a chemical reaction. TES systems are applied in several sectors as concentrated solar power [18], waste heat [19], buildings sector [20], etc.

The main issue that should be considered when applying the TES technology is the price and therefore the scientific community is pushing a big effort for developing or providing new materials that can achieve the lowest-cost per $\mathrm{kWh}$. Within this scenario, byproducts are highlighted as emergent materials to be considered as TES candidates as reported by Barreneche et al. $(2013,2014)[21,22]$ and Ortega et al. [23,24], where slags were studied as TES media. Moreover, Gutierrez et al. have stated the feasibility of revalorizing wastes or by-products as TES materials although more studies are needed to achieve its industrial deployment [25].

Using by-products and residues as TES materials, such as WBA from the incineration of MSW, not only allows reducing the cost of the system, but also offers a reutilization alternative for avoiding their landfill disposal. By-products can be considered good candidates for TES systems when they possess a high $C p$ for SHTES, high phase change enthalpy $(\Delta H)$ in the case of LHTES, or high reaction enthalpy for TCTES. Taking into account the varying composition of WBA - a conglomerate of glassy, ceramic and metallic materials-, it might be inferred that this type of residue presents thermal features that can be used to store sensible heat. Therefore, the aim of this study is to evaluate the thermophysical properties of WBA as a function of its varying composition in order to find suitable alternatives for its valorization or reutilization, highlighting its potential candidature as TES material alternative.

\section{Materials and methods}

\subsection{Materials}

The samples of weathered bottom ash (WBA) were collected from a waste-to-energy facility located in Tarragona (Spain). The facility managed 140,300 tons of MSW (mainly household waste stream with some commercial contributors) during 2014, producing 2467 tons of scrap iron and 31,100 tons of fresh BA (water quenched). The latter is further processed in a conditioning plant for the recovery of some valuable materials (ferrous and nonferrous metals) and for obtaining a homogenized granular material. After stabilization (natural weathering), this homogenized material is fully reused as secondary building material.

The MSW refuse fraction that is treated in this facility is further processed in a conditioning plant for the recovery of some valuable materials (mainly ferrous and non-ferrous metals) in order to obtain a homogenized granular material that after natural weathering can be reused as secondary building material. It was at the outlet of the waste-to-energy facility before the conditioning process where sampling took place. Three hourly successive samples of approximately $25 \mathrm{~kg}$ was collected and labeled as (S1, S2 and S3).

It is important to highlight that changes in MSW composition are influence by several factors such as the season, the economic level of the population, the number of inhabitants and whether it is an urban or rural area [26]. This fact was studied by Chimenos et al. [5] and changes in the composition of bottom ash (WBA) are regarded as low because the major components of this material are ceramics, mainly glass and building material(up to $80 \% \mathrm{wt}$.), which fluctuations over time are very small for a specific facility. Thus, due to the slight changes in composition, thermal storage capacity can be also considered to remain invariant over time.

In addition, TES charging and discharging processes will depend on the material composition, therefore, further research is required in order to understand the thermal and thermal cycling stability of the different fraction size of the WBA as well as their thermal performance within a TES system.

\subsection{Methodology}

\subsubsection{Characterization of the WBA samples}

Each sample (S1, S2 and S3) was homogenized by quartered and sieved in different sized prior to take representative sub-samples of about $5 \mathrm{~kg}$ for the materialographic classification for each size. The particle size distribution of each sub-sample was determined following the same procedure carried out by Ref. [5]. This consisted in sieving each sub-sample by mechanical shaking with stainless steel mesh screens with openings of standard $0.063,1,2,4,8$ and $16 \mathrm{~mm}$ in EN 933-2 sieves. It should be highlighted that the thermal stability of these samples, due to their previous high-temperature thermal treatment, must be ensured but further work is required in this field; moreover, thermal cycling stability should be assessed. If this material is thermally stable over $200-300^{\circ} \mathrm{C}$, it can be applied for industrial applications such as waste heat recovery, solar cooling, etc.

After sieving, each fraction was carefully washed successively with cool tap water through the sieve in order to separate fines adhered to coarse particles. The samples with sizes below $4 \mathrm{~mm}$ where further washed with hydrochloric acid $(50 \% \mathrm{v} / \mathrm{v})$ and then dried at $105{ }^{\circ} \mathrm{C}$ for $24 \mathrm{~h}$. The samples with a particle size above $4 \mathrm{~mm}$ were classified visually while the $4-2 \mathrm{~mm}$ fraction was classified by the aid of a magnifying glass. The classification took into account five types of materials $[5,6]$ : ceramics (both natural and synthetic), non-ferromagnetics (non-ferrous metals), ferromagnetics (ferrous metals), glass (both primary and secondary glass), and unburned carbonaceous matter (CM). The collection of ferromagnetics was performed prior the visual classification by spreading the sample and placing a magnet over it at a distance of $10 \mathrm{~cm}$ height.

Because of the impracticability of visually classifying the fine fractions (0-0.063, 0.063-1, and 1-2 mm), all samples under study were milled by means of a ball milling under $200 \mathrm{rpm}$ during $5 \mathrm{~min}$ to achieve the sample samples size $(0-1 \mathrm{~mm})$ and allowed their physicochemical and thermal characterization. Each sample (including the grinded coarse fractions that were reduced to a 
0-1 mm fraction) was chemically characterized using X-ray Fluorescence (XRF) and X-ray Diffraction (XRD). For the former, a Philips PW2400 X-ray sequential spectrophotometer was used to elucidate major and minor elements while for the latter a Bragg-Brentano Siemens D-500 powder diffractometer with $\mathrm{CuK} \alpha$ radiation was used for determining the crystalline phases. The bulk density was measured with helium pycnometer while the specific density measurements were performed by means of the Archimedes' principle. Both density measurements (bulk density and specific density) were used to calculate the energy density.

\subsubsection{Thermophysical characterization}

Differential scanning calorimetry (DSC) is one of the main techniques used to evaluate the thermophysical performance of the materials by measuring the sensible heat, latent heat, $C p$, phase change temperatures, etc. DSC is able to measure the energy involved in the existing energy processes appeared under a temperature ramp or an isothermal procedure. The DSC measurements were performed from $100{ }^{\circ} \mathrm{C}$ to $500{ }^{\circ} \mathrm{C}$ under a heating rate of $10{ }^{\circ} \mathrm{C} \cdot \mathrm{min}^{-1}$. Around $25 \mathrm{mg}$ of the selected sample were placed inside a $100 \mu \mathrm{L}$ aluminum crucible under $50 \mathrm{~mL} \cdot / \mathrm{min}^{-1} \mathrm{~N}_{2}$ flow and the measurements were calibrated with $25 \mathrm{mg}$ sapphire. The instrument used was DSC822e from Mettler Toledo. The DSC analyses performed were used to characterize the $C p$ at several temperatures $\left(100^{\circ} \mathrm{C}, 150^{\circ} \mathrm{C}, 200^{\circ} \mathrm{C}, 250^{\circ} \mathrm{C}, 300^{\circ} \mathrm{C}, 350^{\circ} \mathrm{C}, 400^{\circ} \mathrm{C}, 450{ }^{\circ} \mathrm{C}\right.$, and $\left.500{ }^{\circ} \mathrm{C}\right)$. The measurements were used for calculating the material energy density $\left(\rho_{\text {en }}\right)$ following Eq. (1), where $\rho$ is the specific/bulk density of the material and $C_{p}$ is its specific heat.

The density values used to calculate the $\rho_{\text {en }}$ were obtained by means of the helium picnometer. The highest the $\rho_{e n}$, the highest the TES capacity of the material although the thermal gradient applied must be also taken into consideration.

$\rho_{\text {en }}=C_{p} \cdot \rho$

\section{Results and discussion}

\subsection{Materialographic characterization}

Fig. 1 shows the average classification results of the three WBA samples obtained by visual methods. As it can be seen, the results were very similar among replicates (low standard deviation), which allows considering a good reproducibility and representation of the classification method. The high percentage of ceramic components in the coarse fraction ( $>16 \mathrm{~mm}$ ), which was comprised between 60 and $70 \%$ of the total content and gradually decreased along the size fraction until $4 \mathrm{~mm}$, was quite noticeable. The main components of this material are mainly attributed to fragments of cement, concrete, pottery, brickbat, porcelain, and gypsum. The values are significantly higher than those previously reported by Chimenos et al., revealing the great role that ceramics play in the current WBA composition [5]. The content of ferrous metals ranged from 20 to $30 \mathrm{wt} \%$ for all size fractions except for the $16-8 \mathrm{~mm}$, which was below $10 \mathrm{wt} \%$. The nature of coarse ferrous metals was different to that of smaller fractions. The coarse fraction $(>16 \mathrm{~mm}$ ) was mainly formed by pieces of steel and iron oxidized in the combustion furnace while small size fractions (4-2 $\mathrm{mm}$ ) were mainly formed by magnetized sand. The content of non-ferromagnetic metals was substantially lower, with increasing percentages as size fraction decreased, ranging from 5 to $20 \mathrm{wt} \%$. Included in this category was aluminium, whose content accounted to be the most relevant $(60 \%$ on average), while other metals such as copper, brass, and gold were observed in lower amounts [23]. The quantity of unburned carbonaceous matter (C.M.) ranged from 1 to $3.5 \mathrm{wt} \%$, and consisted basically in plastic trash bags, synthetic fibres, wood fragments and to a lesser extent carbonaceous semi-burned granulates [5]. In order to assess the glass content, all the unchanged glass bottles particles and coloured packaging glass (termed as primary glass) were considered along with the glass phases formed during combustion (termed as secondary glass). Thus, glass was the major component in medium-sized fractions (16-4 mm), decreasing as size fraction decreased. This behaviour is attributed to recycling programs, as entire glass bottles (beer, wine and other food, and beverages packaging) are easily recycled, depleting the content of glass in the coarse fractions of MSW refuse and hence on WBA. Moreover, packaging glass is a rigid brittle material that undergoes fracture easily during waste transportation and incineration, easing the breaking into smaller pieces.

\subsection{Chemical characterization}

The average composition of the three samples of WBA as a

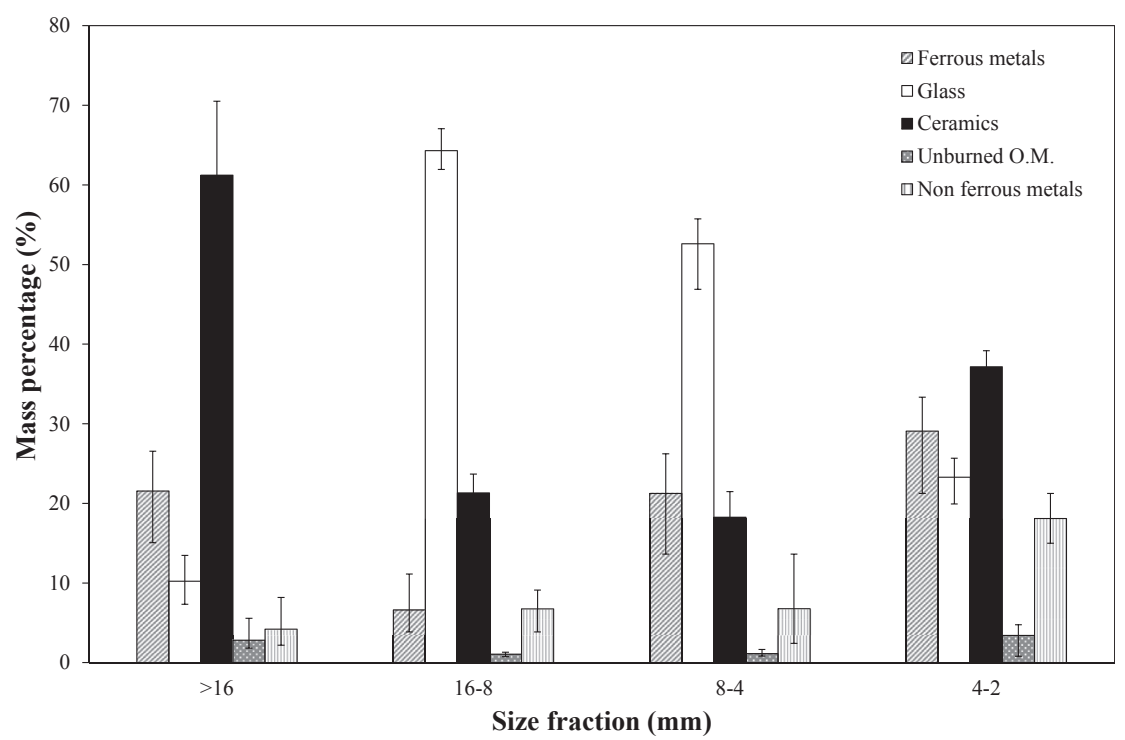

Fig. 1. Materialographic classification of WBA as a function of the coarse and intermediate size fractions. 
function of the size fraction, as determined by XRF, is given in Table 1 for each determined element as the most stable corresponding oxide. The coarsest fraction (above $16 \mathrm{~mm}$ ) was not considered for the XRF and XRD analysis because grinding such large particles was considered to be not representative. Moreover, the visual classification method was especially more accurate to this fraction. As it can be seen, silica was the major compound in all size fractions, being increased as the size fraction increased. Thus, according to visual classification (see Fig. 1), not all the $\mathrm{SiO}_{2}$ content in the $>16 \mathrm{~mm}$ fraction comes from amorphous glass (packaging glass) but also from ceramic sources. Nevertheless, almost the total content of silica in the intermediate fractions (4-8 and 2-4 mm) can be attributed to amorphous glass. The same conclusion can be drawn for $\mathrm{CaO}$ (which decreased as size increased) and the content of ceramics, although the contribution of other compounds such as $\mathrm{MgO}$ and $\mathrm{Al}_{2} \mathrm{O}_{3}$ should be also taken into consideration for this kind of materials. The content of ferrous metals from visual classification was slightly higher than that of $\mathrm{Fe}_{2} \mathrm{O}_{3}$, considering this compound as the most stable oxide for iron. This can be attributed to the fact that during grinding of the samples prior XRF analysis, several pieces of metallic iron remained larger enough for requiring extraction. The content of $\mathrm{Al}_{2} \mathrm{O}_{3}$ was in close agreement with the tendency of non-ferrous metals content from visual classification and with that reported elsewhere, with minor contribution from $\mathrm{CuO}[6,15,27]$. The results obtained from XRD analysis (not shown), allowed identifying quartz and calcite as the major crystalline phases in all size fractions, in accordance to the results drawn from the XRF analysis. Different kinds of non-stoichiometric phases of iron were also identified, as well as complex calcium compounds, especially in the coarse fractions above $1 \mathrm{~mm}$. Many of these phases have their origin in the combustion chamber during incineration and also during the weathering process.

\subsection{Thermophysical characterization}

The results of $C p$ obtained from the DSC analysis are shown in Table 2 along with the bulk density values and the calculated energy density $\rho_{e n}$. The $\rho_{e n}$ calculations took into account the bulk density since the materials under study were measured with the same size (0-1 mm, see section 2.2.1) and the same air inside the sample. It can be assumed that energy density increases with temperature. The $1-2 \mathrm{~mm}$ and $4-8 \mathrm{~mm}$ size fractions presented the highest $C p$ (the maximum value of $0.51 \mathrm{~kJ} \mathrm{~kg}^{-1} \mathrm{~K}^{-1}$ for $1-2 \mathrm{~mm}$ at $\left.500{ }^{\circ} \mathrm{C}\right)$ while the finest fraction $(0-0.063 \mathrm{~mm})$ showed the lowest values at $500{ }^{\circ} \mathrm{C}\left(0.01 \mathrm{~kJ} \mathrm{~kg}^{-1} \mathrm{~K}^{-1}\right)$. The bulk density

Table 1

Average composition of WBA determined by XRF as a function of size fraction.

\begin{tabular}{lllllll}
\hline Oxides & \multicolumn{5}{l}{ Size fraction $(\mathrm{mm})$} \\
\cline { 2 - 7 } & $0-0.063$ & $0.063-1$ & $1-2$ & $2-4$ & $4-8$ & $8-16$ \\
\hline $\mathrm{SiO}_{2}$ & 27.56 & 27.87 & 34.35 & 49.33 & 47.78 & 55.36 \\
$\mathrm{CaO}$ & 27.23 & 27.55 & 21.16 & 15.82 & 17.04 & 13.25 \\
$\mathrm{Fe}_{2} \mathrm{O}_{3}$ & 12.48 & 10.64 & 16.66 & 10.45 & 11.01 & 8.45 \\
$\mathrm{Al}_{2} \mathrm{O}_{3}$ & 9.64 & 10.52 & 10.03 & 9.47 & 7.86 & 5.06 \\
$\mathrm{P}_{2} \mathrm{O}_{5}$ & 3.13 & 3.07 & 2.58 & 1.36 & 1.83 & 0.412 \\
$\mathrm{MgO}$ & 3.12 & 3.16 & 3.42 & 2.28 & 2.97 & 1.87 \\
$\mathrm{SO}_{3}$ & 2.31 & 2.69 & 1.13 & 0.203 & 0.361 & 0.138 \\
$\mathrm{Na}_{2} \mathrm{O}$ & 1.95 & 2.30 & 3.66 & 8.28 & 7.37 & 8.83 \\
$\mathrm{~K}_{2} \mathrm{O}$ & 1.26 & 1.53 & 1.50 & 1.14 & 1.21 & 1.18 \\
$\mathrm{TiO}_{2}$ & 0.91 & 0.868 & 0.796 & 0.534 & 0.390 & 0.170 \\
$\mathrm{ZnO}$ & 0.463 & 0.521 & 0.333 & 0.133 & 0.134 & - \\
$\mathrm{PbO}$ & 0.109 & - & 0.124 & 0.108 & - & - \\
$\mathrm{Cl}$ & 0.461 & 0.643 & 0.192 & - & - & - \\
$\mathrm{CuO}$ & 0.164 & 0.217 & 0.240 & - & 0.126 & 0.239 \\
$\mathrm{MnO}$ & 0.134 & 0.112 & 0.117 & - & - & - \\
\hline
\end{tabular}

values obtained by Helium pycnometer were very similar among size fractions, ranging from 2579 to $2962 \mathrm{~kg} \mathrm{~m}^{-3}$. Notice that the density used to calculate the energy density was the bulk density since the DSC measurements was performed using the previously milled samples. Accordingly, the highest energy density was observed for the $1-2 \mathrm{~mm}$ fraction (1461.2 $\mathrm{kJ} \mathrm{m}^{-3} \mathrm{~K}^{-1}$ ), which can be attributed to its highest metal content and other iron phases (see Table 2). The $4-8 \mathrm{~mm}$ fraction presented a similar energy density (1186.3 $\mathrm{kJ} \mathrm{m}^{-3} \mathrm{~K}^{-1}$ ), although its higher $\mathrm{SiO}_{2}$ content and lower presence of iron and aluminum could have decreased its thermal performance. Therefore, energy density was significantly related to the content of metals and to a lesser extent to the amount of $\mathrm{SiO}_{2}$. This is in accordance with the energy density observed for the 8-16 mm fraction, whose $\mathrm{SiO}_{2}$ content was the highest observed with an average metallic content. Thus, the deficiency in metals was compensated with higher silica content: the coarse fraction (8-16 mm) presented the highest silica content (55.4 wt \%) that compensated the lowest metal content. On the other hand, it is important to emphasize that the finest fraction $(0-0.063 \mathrm{~mm})$ presented the lowest energy density at medium $\mathrm{SiO}_{2}, \mathrm{Fe}_{2} \mathrm{O}_{3}$ and $\mathrm{Al}_{2} \mathrm{O}_{3}$ contents. Hence, the lowest silica content was not compensated by the moderate metallic content. Fig. 2 illustrates this effect where Cp vs. density [24] (Fig. 2a - bulk density; Fig. 2b - specific density) of the samples under study and the main components of the sample as $\mathrm{SiO}_{2}, \mathrm{Fe}_{2} \mathrm{O}_{3}, \mathrm{Al}_{2} \mathrm{O}_{3}$, etc. are overlapped. Therefore, all samples under study have a moderate $C p$ in comparison with the individual main components although the density values are within the average. It's important to highlight that the density values are slightly different between bulk and specific density results (Fig. 2a and b respectively) due to the initial material size and the material porosity. However, the order of magnitude is similar.

Moreover, Fig. 3 shows the energy density vs. the price of the materials under study and materials used as sensible heat TES materials in order to compare the amount of heat that each material is able to store in such a volume and a comparison between the prices of the materials commonly used to store energy as sensible heat. Taking into account the classification performed in previous studies [21,22], the energy density of MSWI bottom ash studied in this research is in the same range of other by-products (Fig. 3) although at a lower cost $(0.6 € /$ tn according to the data provided by the VECSA company). The price of WBA is even lower than WDF, which is the powder material produced during the steelmaking process in electric arc furnace [22].

\section{Conclusions}

The revalorization of waste or by-products as TES materials allows reducing the cost of the system while offering a reutilization alternative for avoiding their landfill disposal. This is in accordance with the European directives of recycling and sustainability since it would contribute to energy savings while reusing residues. The literature has already reported a few studies on this aspect and an intense research is needed in order to attain its industrial deployment. In this study, different size fractions of weathered bottom ash (WBA) from the incineration of municipal solid waste (MSW) residues were characterized with respect its physicochemical and thermal properties. The results obtained showed that this residue is a suitable alternative candidate material for TES as the highest energy density was $1461.2 \mathrm{~kJ} \mathrm{~m}^{-3} \mathrm{~K}^{-1}$ for the $1-2 \mathrm{~mm}$ fraction. According to the physicochemical characterization carried out for each size fraction, this is attributed to its high metal content. In this sense, energy density $\left(\rho_{e n}\right)$ was significantly related to the content of metals and to a lesser extent to the amount of $\mathrm{SiO}_{2}$ presented in WBA. The results of $C p$ vs. bulk and specific density for each size fraction were compared to those from $\mathrm{Al}_{2} \mathrm{O}_{3}, \mathrm{SiO}_{2}, \mathrm{CaCO}_{3}$, and $\mathrm{CaO}$. 
Table 2

Thermophysical characterization: density, Cp, Energy density.

\begin{tabular}{|c|c|c|c|c|c|c|c|}
\hline \multirow[t]{2}{*}{ Bulk density $-\rho\left(\mathrm{Kg} \cdot \mathrm{m}^{-3}\right)$} & \multirow[t]{2}{*}{ Temperature ${ }^{\circ} \mathrm{C}$} & \multirow{2}{*}{$\frac{0-0.063 \mathrm{~mm}}{2733}$} & \multirow{2}{*}{$\frac{0.063-1 \mathrm{~mm}}{2962}$} & \multirow{2}{*}{$\frac{1-2 \mathrm{~mm}}{2865}$} & \multirow{2}{*}{$\frac{2-4 \mathrm{~mm}}{2805}$} & \multirow{2}{*}{$\frac{4-8 \mathrm{~mm}}{2579}$} & \multirow{2}{*}{$\frac{8-16 \mathrm{~mm}}{2586}$} \\
\hline & & & & & & & \\
\hline \multirow[t]{9}{*}{ Specific heat $-C_{p}\left(\mathrm{~kJ} \mathrm{~kg}^{-1} \cdot \mathrm{K}^{-1}\right)$} & $100{ }^{\circ} \mathrm{C}$ & 0.08 & 0.08 & 0.15 & 0.10 & 0.20 & 0.26 \\
\hline & $150{ }^{\circ} \mathrm{C}$ & 0.10 & 0.18 & 0.31 & 0.20 & 0.37 & 0.31 \\
\hline & $200^{\circ} \mathrm{C}$ & 0.10 & 0.15 & 0.31 & 0.19 & 0.37 & 0.30 \\
\hline & $250^{\circ} \mathrm{C}$ & 0.08 & 0.14 & 0.32 & 0.17 & 0.20 & 0.34 \\
\hline & $300{ }^{\circ} \mathrm{C}$ & 0.04 & 0.14 & 0.35 & 0.16 & 0.37 & 0.24 \\
\hline & $350{ }^{\circ} \mathrm{C}$ & 0.02 & 0.17 & 0.38 & 0.16 & 0.39 & 0.25 \\
\hline & $400{ }^{\circ} \mathrm{C}$ & 0.01 & 0.20 & 0.42 & 0.17 & 0.41 & 0.26 \\
\hline & $450{ }^{\circ} \mathrm{C}$ & 0.01 & 0.23 & 0.47 & 0.17 & 0.43 & 0.27 \\
\hline & $500{ }^{\circ} \mathrm{C}$ & 0.01 & 0.24 & 0.51 & 0.17 & 0.46 & 0.29 \\
\hline \multirow[t]{9}{*}{ Energy density $-\rho_{\text {en }}\left(\mathrm{kJ} \mathrm{m}^{-3} \mathrm{~K}^{-1}\right)$} & $100{ }^{\circ} \mathrm{C}$ & 218.6 & 237.0 & 429.8 & 280.5 & 515.8 & 672.4 \\
\hline & $150{ }^{\circ} \mathrm{C}$ & 273.3 & 533.2 & 888.2 & 561.0 & 954.2 & 801.7 \\
\hline & $200{ }^{\circ} \mathrm{C}$ & 273.3 & 444.3 & 888.2 & 533.0 & 954.2 & 775.8 \\
\hline & $250{ }^{\circ} \mathrm{C}$ & 218.6 & 414.7 & 916.8 & 476.9 & 515.8 & 879.2 \\
\hline & $300{ }^{\circ} \mathrm{C}$ & 109.3 & 414.7 & 1002.8 & 448.8 & 954.2 & 620.6 \\
\hline & $350{ }^{\circ} \mathrm{C}$ & 54.7 & 503.5 & 1088.7 & 448.8 & 1005.8 & 646.5 \\
\hline & $400{ }^{\circ} \mathrm{C}$ & 27.3 & 592.4 & 1203.3 & 476.9 & 1057.4 & 672.4 \\
\hline & $450{ }^{\circ} \mathrm{C}$ & 27.3 & 681.3 & 1346.6 & 476.9 & 1109.0 & 698.2 \\
\hline & $500{ }^{\circ} \mathrm{C}$ & 27.3 & 710.9 & 1461.2 & 476.9 & 1186.3 & 749.9 \\
\hline
\end{tabular}

a)

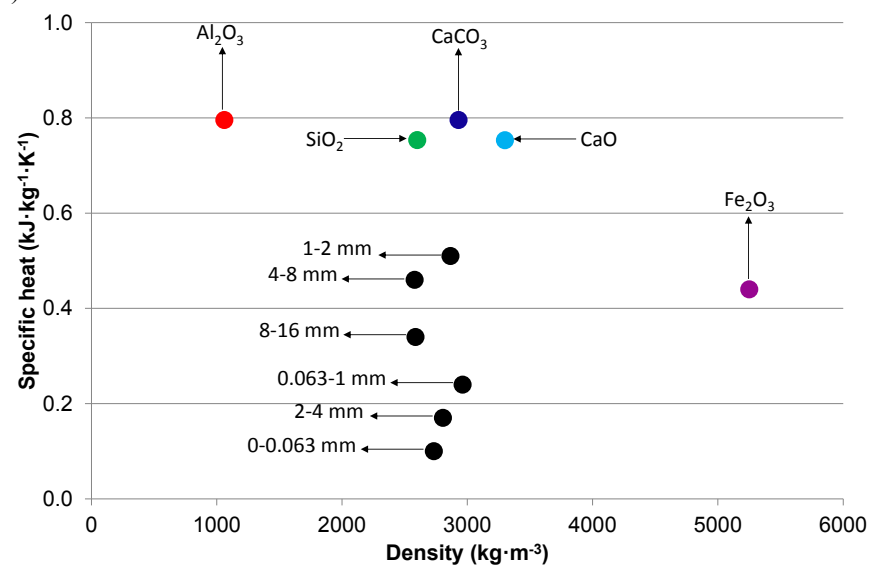

b)

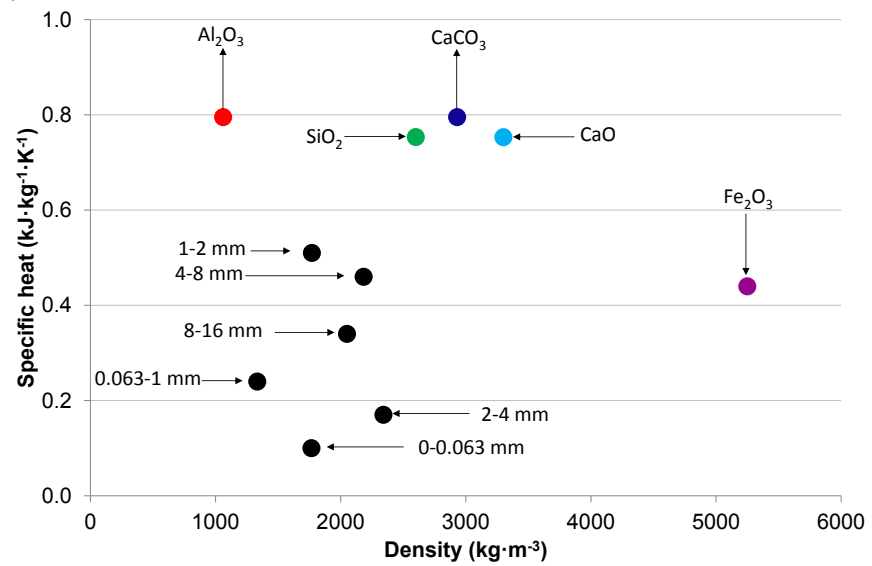

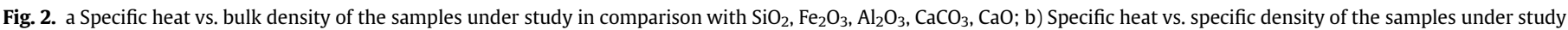
in comparison with $\mathrm{SiO}_{2}, \mathrm{Fe}_{2} \mathrm{O}_{3}, \mathrm{Al}_{2} \mathrm{O}_{3}, \mathrm{CaCO}_{3}, \mathrm{CaO}$ [24].

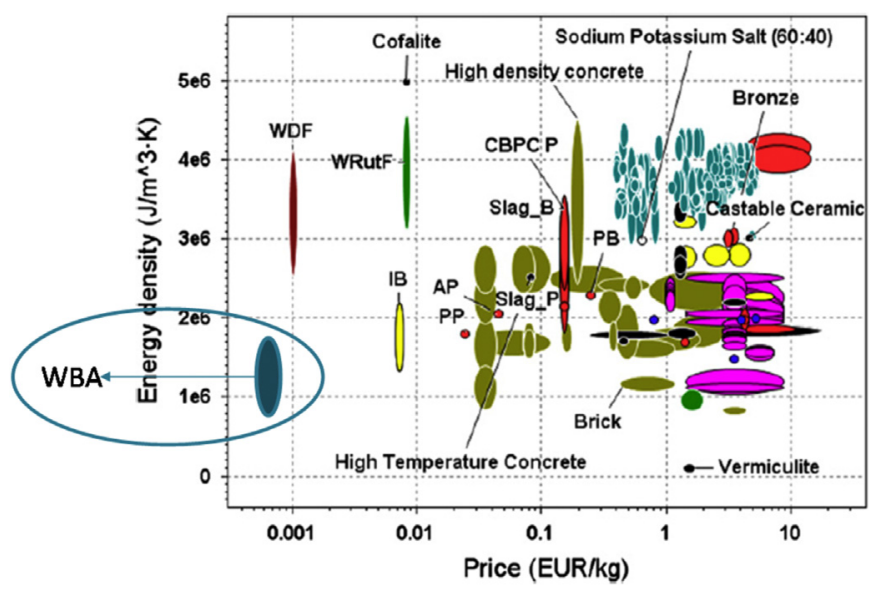

Fig. 3. Energy density vs. Cost of by product materials used for TES - adapted from Ref. [22].
These are the main compounds in WBA. Thus, all size fractions presented a moderate $C p$ in comparison with the individual main components although the density values were within the average. The lower cost of this type of residue $(0.6 € /$ tn according to the data provided by the VECSA company) and its high production rate per year makes WBA attractive for its reutilization.

\section{Acknowledgements}

The authors would like to thank the SIRUSA and VECSA companies for their financial support and for providing the sample. The authors would like to thank the Catalan Government for the quality accreditation given to the research group GREA (2014 SGR 123) and DIOPMA (2014 SGR 1543). The research leading this project has received funding from the European Commission Seventh Framework Programme (FP/2007-2013) under Grant agreement N ${ }^{\circ}$ PIRSES-GA-2013-610692 (INNOSTORAGE) and from the European Union's Horizon 2020 research and innovation programme under grant agreement No 657466 (INPATH-TES). Dr. Camila Barreneche would like to thank Ministerio de Economia y Competitividad de España for Grant Juan de la Cierva, FJCI-2014-22886. 


\section{References}

[1] R. del Valle-Zermeño, J. Formosa, J.M. Chimenos, M. Martínez, A.I. Fernández, Aggregate material formulated with MSWI bottom ash and APC fly ash for use as secondary building material, Waste Manag. 33 (2013) 621-627, http:// dx.doi.org/10.1016/j.wasman.2012.09.015.

[2] C.H.K. Lam, A.W.M. Ip, J.P. Barford, G. McKay, Use of incineration MSW ash: a review, Sustainability 2 (2010) 1943-1968, http://dx.doi.org/10.3390/ su2071943.

[3] G. Chen, N. Zhang, W. Ma, V.S. Rotter, Y. Wang, Investigation of chloride deposit formation in a 24 MWe waste to energy plant, Fuel 140 (2015) 317-327.

[4] M. Izquierdo, A. López-Soler, E.V. Ramonich, M. Barra, X. Querol, Characterisation of bottom ash from municipal solid waste incineration in Catalonia, J. Chem. Technol. Biotechnol. 77 (2002) 576-583.

[5] J.M. Chimenos, M. Segarra, M.A. Fernández, F. Espiell, Characterization of the bottom ash in municipal solid waste incinerator, J. Hazard. Mater. 64 (1999) $211-222$.

[6] R. del Valle-Zermeño, J. Giró-Paloma, J.C.J. Formosa, Glass content in MSWl bottom ash: effectiveness assessment of recycling over time, in: Raffaello Cossu (Ed.), Second Symp. Urban Min, Eurowaste Srl, Bergamo, Italy, 2014.

[7] A.J. Chandler, Municipal Solid Waste Incinerator Residues Studies in Environmental Sciences, Elsevier Science Publishers B.V., Amsterdam, Netherlands, 1997.

[8] J.M. Chimenos, A.I. Fernández, L. Miralles, M. Segarra, F. Espiell, Short-term natural weathering of MSWI bottom ash as a function of particle size, Waste Manag. 23 (2003) 887-895, http://dx.doi.org/10.1016/S0956-053X(03)000746.

[9] M. Fernández Bertos, X. Li, S.J.R. Simons, C.D. Hills, P.J. Carey, Investigation of accelerated carbonation for the stabilisation of MSW incinerator ashes and the sequestration of $\mathrm{CO} 2$, Green Chem. 6 (2004) 428-436, http://dx.doi.org/ $10.1039 / \mathrm{b} 401872 \mathrm{a}$.

[10] R. Del Valle-Zermeño, J. Formosa, M. Prieto, R. Nadal, M. Niubó, J.M. Chimenos, Pilot-scale road subbase made with granular material formulated with MSWI bottom ash and stabilized APC fly ash: environmental impact assessment, J. Hazard. Mater. 266 (2014) 132-140.

[11] T. Sabbas, A. Polettini, R. Pomi, T. Astrup, O. Hjelmar, P. Mostbauer, et al., Management of municipal solid waste incineration residues, Waste Manag. 23 (2003) 61-88.

[12] P. Tatsidjodoung, N. Le Pierrès, L. Luo, A review of potential materials for thermal energy storage in building applications, Renew. Sustain. Energy Rev. 18 (2013) 327-349.

[13] R. del Valle-Zermeño, J.M. Chimenos, J. Giro-Paloma, J. Formosa, Use of weathered and fresh bottom ash mix layers as a subbase in road constructions: environmental behavior enhancement by means of a retaining barrier, Chemosphere 117 (2014) 402-409.

[14] J.D. Eusden, T.T. Eighmy, K. Hockert, E. Holland, K. Marsella, Petrogenesis of municipal solid waste combustion bottom ash, Appl. Geochem. 14 (1999) 1073-1091.

[15] L. Biganzoli, A. Ilyas, M.V. Praagh, K.M. Persson, M. Grosso, Aluminium recovery vs. hydrogen production as resource recovery options for fine MSWI bottom ash fraction, Waste Manag. 33 (2013) 1174-1181.

[16] Fifth Assessment Report - Synthesis Report n.d. http://www.ipcc.ch/report/ ar5/syr/(accessed May 11, 2015).

[17] D. Ürge-Vorsatz, L.F. Cabeza, S. Serrano, C. Barreneche, K. Petrichenko, Heating and cooling energy trends and drivers in buildings, Renew. Sustain. Energy Rev. 41 (2015) 85-98. http://dx.doi.org/10.1016/j.rser.2014.08.039.

[18] C. Prieto, R. Osuna, A.I. Fernández, L.F. Cabeza, Molten salt facilities, lessons learnt at pilot plant scale to guarantee commercial plants; heat losses evaluation and correction, Renew. Energy 94 (2016) 175-185, http://dx.doi.org 10.1016/j.renene.2016.03.039.

[19] J. Yagi, T. Akiyama, Storage of thermal energy for effective use of waste heat from industries, J. Mater. Process Technol. 48 (1995) 793-804, http:/ dx.doi.org/10.1016/0924-0136(94)01723-E.

[20] I. Dincer, On thermal energy storage systems and applications in buildings, Energy Build. 34 (2002) 377-388, http://dx.doi.org/10.1016/S0378-7788(01) 00126-8.

[21] C. Barreneche, M.E. Navarro, M. Niubó, L.F. Cabeza, A.I. Fernández, Use of PCMpolymer composite dense sheet including EAFD in constructive systems, Energy Build. 68 (2014) 1-6.

[22] C. Barreneche, Development and Characterization of New Materials Incorporating Phase Change Materials (PCM) for Thermal Energy Storage (TES) Applications in Buildings, University of Lleida, 2013.

[23] I. Ortega-Fernández, N. Calvet, A. Gil, J. Rodríguez-Aseguinolaza, A. Faik B. D'Aguanno, Thermophysical characterization of a by-product from the steel industry to be used as a sustainable and low-cost thermal energy storage material, Energy 89 (2015) 601-609, http://dx.doi.org/10.1016/ j.energy.2015.05.153.

[24] I. Ortega, J. Rodríguez-Aseguinolaza, A. Gil, A. Faik, B. D'Aguanno, New thermal energy storage materials from industrial wastes: compatibility of steel slags with the most common heat transfer fluids, Comb. Energy Cycles, CHP CCHP, Smart Grids; Conc. Sol. Power, Sol. Thermochem. Therm. Energy Storage; Geothermal, Ocean. Emerg. Energy Technol. Hydrog. Energy Technol. Low/ Zero Emiss. Power Plants an, vol. 1, ASME, p. V001T02A010 1 (2014), http:/ dx.doi.org/10.1115/ES2014-6369.

[25] A. Gutierrez, L. Miró, A. Gil, J. Rodríguez-Aseguinolaza, C. Barreneche $\mathrm{N}$. Calvet, et al., Advances in the valorization of waste and by-product materials as thermal energy storage (TES) materials, Renew. Sustain. Energy Rev. 59 (2016) 763-783.

[26] G. Tchobanoglous, H. Theisen, S. Vigil, Integrated Solid Waste Management: Engineering Principles and Management Issues, McGraw-Hill, 1993.

[27] L. Biganzoli, M. Grosso, F. Forte, Aluminium mass balance in waste incineration and recovery potential from the bottom ash: a case study, Waste Biomass Valorization 5 (2014) 139-145. 